\title{
РАЗДЕЛЕНИЕ ОТВЕТСТВЕННОСТИ В ДИНАМИЧНОМ ОРГАНИЗАЦИОННОМ РАЗВИТИИ ВЫСОКОТЕХНОЛОГИЧНЫХ КОРПОРАЦИЙ
}

\author{
(c) 2018 Базадзе Наталья Григорьевна \\ доктор экономических наук, профессор \\ профессор кафедры «Менеджмент и маркетинг высокотехнологичных отраслей промышленности» \\ Московский авиационный институт (Национальный исследовательский университет) \\ 125993, г. Москва, Волоколамское шоссе, 4 \\ E-mail: n-bazadze@yandex.ru
}

Управление развитием корпоративной структуры как целостной организационной системой в высокотехнологичной среде требует декомпозиции бизнес-процессов по иерархическим уровням управления для разделения ответственности за результаты на все уровни управления, включая и самих исполнителей для устойчивости и гибкости реакции системы на растущие потоки изменений.

Ключевые слова: организационное развитие, динамичное развитие, бизнес-процессы, редукция процессов, внешние человеческие ресурсы, внутренние человеческие ресурсы, разделение ответственности

\section{1. Актуальность}

В новой экономике крупным корпоративным структурам, работающим на рынках высоких технологий, или использующим инновационные технологии для выпуска массовых товаров и реализации массовых услуг, взявшим курс на долгосрочные стратегии развития, все сложнее разрешать конфликты между требованиями обеспечивать целостность и управляемость иерархической структурой и гибкостью реакции на динамичные изменения рыночной среды. Высокие технологии заметно влияют на жизнь общества, не только за счет создания новых продуктов, повышения качества, формирования новых потребительских свойств традиционных продуктов. Они вносят существенные изменения в рабочее и окружающее пространство населения страны и региона. Полномочия распоряжаться ресурсами, выделенными под освоение новых технологий, распределяются в первую очередь. Ответственность за последствия зачастую повисает в воздухе. В числе объективных причин - отсутствие аппарата декомпозиции, редукции процессов хозяйственной деятельности предприятия, его бизнес-процессов по уровням и направлениям ответственности. Представление динамичного состояния предприятий, входящих в состав корпораций, объединенных единой корпоративной культурой управления, через совокупность бизнес-процессов, декомпозированных по уровням управления и развертыванием на каждом уровне процесса работы всех руководителей и исполнителей по требованиям современного управления, сочетающего инстру- менты менеджмента и администрирования, позволит решить эту задачу.

2. Изменения в практиках корпоративного управления

Развитие организации в условиях конкурентного рынка и создания новых рынков, отвечающее, а лучше упреждающего изменения рыночной и политической конъюнктуры, обеспечивают не только технологические, но и организационно-управленческие инновации. Стратегический менеджмент в корпоративных структурах активно осваивается в части стратегического планирования. Вторая часть стратегического менеджмента - реализация стратегических планов, освоена гораздо в меньшей степени. Сегодня развитие крупных высокотехнологичных корпораций в Москве обеспечено созданием служб, функциональная ответственность которых сосредоточена в зоне адаптации структуры управления под новые условия и оптимизации бизнес-процессов - это службы организационного развития, организационного проектирования, подразделения по анализу и оптимизации бизнес-процессов с службах IT, развития бизнеса, организации управления. Мониторинг рынка труда в Москве в октябре 2018 года по поисковикy Head Hanter показал ежедневное наличие более 30 открытых вакансий только по категориям специалистов, таким, как - инженер, специалист, эксперт, аналитик, менеджер, и по такому функционалу как организационное развитие, организационное проектирование, организационное планирование, анализ и оптимизация бизнес-процессов. В практике отечественного 
управления должность менеджера до сих пор рассматривается как должность, относящаяся к категории «специалист», несмотря на отнесение ее в Квалификационном справочнике должностей к категории «руководитель». Судя по функционалу и требованиям, которые указываются в данных вакансиях, рад компаний только открывает соответствующие подразделения, в других меняется лидер данного направления.

В Подмосковье и других крупных промышленных городах России эта цифра пока в 5-10 раз ниже. В меньшем количестве открываются вакансии для руководителей подразделений. Однако включение в функционал других подразделений и должностей ряда обязанностей по анализу и оптимизации бизнес процессов показывают значительно более высокий уровень запросов.

3. Выделение бизнес-процессов В отдельную область управления

Развитие работающей на динамичном рынке корпоративной структуры вследствие масштабности ее деятельности, наличия многоуровневой структуры управления, значительной численностью персонала, распределенной на различных территориальных площадках и обладающих различным набором функциональных обязанностей, предполагает выделение бизнес-процессов в специальную область управления. Стандартизованного определения в российской практике и теории менеджмента не существует, хотя само понятие активно используется. Как любой процесс, бизнес-процесс организации логично представить в виде последовательности (а не совокупности, как указано во многих распространенных источниках) работ, выполняемых участниками процесса, с четко обозначенным входом (началом) и выходом (концом) процесса. Входом бизнес-процесса, является поступление требуемых ресурсов из внешней, рыночной среды. Выходом бизнес-процесса является товар - востребованные рынком (потребителями) продукты/услуги, производимые организацией. Для исследователей, рассматривающих экономику России как рыночную, бизнес-процессы являются, обшей категорией, относящейся ко всем отечественным предприятиям. Автор статьи относится к тем, кто определяет тип экономических отношений в России, как смешанный. Соответственно, как более общее понятие для отечественных предприятий выделяет процессы хозяйственной де- ятельности. Оба понятия следует рассматривать как синонимы.

4. Встраивание функции проектирования процессов в практику отечественного управления

Ряд определений бизнес-процессов в локальных нормативных документах отечественных предприятий указывает на последовательность действий персонала, которые преобразуют ресурсы в продукты/услуги, акцентируя внимание на участие человека и отличие от чисто автоматического (технологического) процесса. И здесь у российских оборонных предприятий в отличие от предприятий непроизводственной сферы, которые выросли в крупные корпоративные структуры в питательной для них рыночной среде и с легкостью приняли на вооружение западные методы управления (а точнее менеджмента), проявляется большее количество проблемных зон. Одна из них, сопряжение концепций и методов конструирования новых изделий и технологирования процессов их производства и технологирования процессов управления, обслуживания, обеспечения производства. Термин «технологирование» как разработку технологий и технологических процедур на повторяющиеся управленческие процессы ввел в 80-х годах прошлого века Федор Михайлович Русинов - один из первых отечественных специалистов, исследовавших технологии управления производством. Процессы конструирования и технологирования производства продукции выделены в самостоятельные области профессиональной деятельности и профессиональной подготовки более века назад. Уровень этой профессионализации признается высоким даже нашими конкурентами. Проектирование процессов управления сейчас в большинстве корпоративных структур передано специалистам IT-подразделений., которые занимаются только технологией управления, выстаивая оптимизированные информационные потоки на предприятиях корпораций, упуская из виду трудовую составляющую. Живой труд, трудовые процессы, как производная трудовой деятельности работников предприятия - потерянная область современного управления.

5. Распределение ответственности по внешним человеческим ресурсам корпораций

Анализ и оптимизация процессов управления и обеспечения производства, российскими производственными корпорациями только ос- 
ваиваются преимущественно с помощью зарубежных методик на базе зарубежных информационных систем (например, ERP-систем - SUS, SAP, Oracle или систем Workflow), иногда с помощью отечественных систем, например, 1С. Наибольшие сложности в таком подходе является восприятие и освоение персоналом подразделений пользователей этих информационных продуктов, использование их в процессах своей оперативной деятельности.

Предлагаемая в данной статье авторская модель хозяйственной деятельности предприятия, отправными точками проектирования представляет внутренние и внешние человеческие ресурсы предприятия. Модель представлена на рисунке в виде редукции процессов хозяйственной деятельности предприятия (как составной части корпорации) внутри контура управления, обозначенного прямоугольником с «мягкими углами». К внешним человеческим ресурсам отнесены те социальные группы, которые оказывают как на текущую, так и перспективную деятельность корпораций значительное влияние. Это те группы, с которыми у корпорации выстроены долгосрочные партнерские отношения. Корпорация, в свою очередь, также оказывает воздействие на эти группы, как в текущем периоде, так и перспективе. За пределами контура управления на рисунке 1 в левом верхнем углу представлены различные социальные группы влияния на хозяйственную деятельность (бизнес) предприятия. Влияние это, как было отмечено выше, двухстороннее - эти группы как сами оказывают влияние на деятельность предприятия, так и подвержены влиянию через последствия от деятельности или принимаемых решений на предприятии. Главная группа влияния обозначена первым номером - потребители, покупатели, клиенты. Это их потребности - явные и скрытые, позволяют формировать объектно-целевое содержание бизнес-процессов (процессов хозяйственной деятельности) предприятия. В качестве объекта рассматривается социальная группа, в качестве цели - потребность, которую предполагается удовлетворять. Назначение данной составляющей - определиться с продуктом/услугой, которую будет выпускать на рынок предприятие. Сколько и какие социальные группы, сколько и какие потребности «закрывают» предприятия выпуском товарной группы определяется в рамках общей стратегии бизнеса.
В инновационной экономике высокотехнологичные корпорации, следуя требованиям корпоративной социальной ответственности, выстаивают долгосрочные партнерские отношения и с другими социальными группами - научно-исследовательскими организациями, учреждениями профессионального образования и культуры, профильными университетами, общественными организациями, органами власти и другими, представленными на рисунке в верхнем левом углу, за контуром управления во внешней среде предприятия. Их интересы и потребности, также попадают в поле зрения проектировщиков системы управления (как архитекторов целостной системы процессов предприятий корпорации) и формулируются в рамках первой объектно-целевой составляющей хозяйственной деятельности (бизнеса).

Ответственность за выстраивание долгосрочных партнерских отношений с этими группами влияния лежит на руководителях высшего звена, возглавляющих подразделения верхнего уровня управления. В российской практике иерархического управления существует большое разнообразие наименований структурных подразделений, которые могут относиться к любому из звеньев управления - управление, отделение, служба, департамент, отдел, лаборатория, сектор. В рамках данной статьи для обозначения подразделения верхнего звена управления выбрано наименование «служба». Под службой предлагается обозначить подразделение, функционал которого представляет собой развертку в процессы групп технологически однородных функций - производство, разработка продукта, исследования рынка, управление финансами, закупки, продажи, обеспечение человеческими ресурсами. Состав и количество функций может и должно меняться с учетом специфики отрасли, возраста предприятия, его положения на рынке. Топ-менеджеры, возглавляющие эти службы должны быть солидарно ответственны за разработку общей стратегии бизнеса. Персонально - за разработку функциональных стратегий своего направления, поддерживающего общую стратегию, выстраивание долгосрочных отношений с группами влияния внешнего контура, а также консолидацию ресурсов, подчиненных подразделений следующего по иерархии подразделений среднего звена и разделение стратегических целей на задачи подразделений следующего уровня управления. 
6. Распределение ответственности по внутренним человеческим ресурсам

К внутренним человеческим ресурсам отнесены все категории работников корпорации, которые теперь на англо-американский манер, принято называть персоналом - руководители всех звеньев управления, специалисты всех подразделений и рабочие всех профессий основного и вспомогательного производства. В процессах организационного развития производственная база представляется не только в статике - как состав и структура производственных мощностей, но и в динамике - как совокупность производственных процессов, в которых участвуют или обеспечивают их бесперебойное протекание (ламинарность потоков) все категории работников.

Реализуемость стратегических планов во многом определяется не столько производственными мощностями предприятия и кадровым потенциалом предприятия, сколько уровнем их организации в едином производственном процессе, где технологические процессы, организация управления технологической подготовкой производства - занимает достойное место в организации производства за счет разработки технологических процессов производства продукции, оснастки, поддержания технологической дисциплины. Компетенции по организации трудовых процессов остались в арсенале только опытных руководителей низовых подразделений старшего поколения. Методическая поддержка и консультации работников отделов и лабораторий научной организации труда исчезла при ликвидации таких подразделений, но частично была восстановлена при создании подразделений по бережливым системам, которые активно осваивались в отечественном авиастроении, автомобилестроении и других высокотехнологичных отраслях экономики.

Исследование и оптимизация трудовых процессов до сих пор относится к области рутинизированных процессов, в первую очередь к труду рабочих и простым видам работ, выполняемых техническими исполнителями и специалистами. Однако, те же бережливые системы, включающие в себя как бережливое производство, так и бережливое управление, указывают на то, что в работе всех категорий лидеров присутствует доля работ, подлежащих стандартизации, которую надо учиться выявлять, изучать и оптимизировать.
Задача сокращения непроизводительных затрат, выливающихся в значительные потери, увеличение проектной стоимости продукции и несоблюдение договорных обязательств, решаема за счет организации работы всех категорий персонала (а не только рабочих) как производительной работы труда в части оперативной деятельности. При этом деятельность высокотехнологичных развивающихся предприятий всегда включает инновационные процессы, организация которых должна строиться на иных подходах. Хотя сейчас при всех проверках контролирующих органов используются одни и те же регламенты операционной и стратегически ориентированной инновационной деятельности, обладающей высокой доли неопределенности и риска.

Предметом исследования, представленного в данной статье, являются процессы производительной работы повторяющихся оперативных обязанностей персонала, организованные как коллективный трудовой процесс.

Организация коллективного трудового процесса - представляет собой соединение во времени и пространстве предметов, средств труда и исполнителей, таким образом, чтобы в результате (на выходе) процесса появился продукт труда, требуемого качества в требуемые сроки. Понятие пространства в данном определении трактуется как рабочее пространство - физическое, где размещаются исполнители и физические (технические) средства труда, и информационное, где четко определено нахождение и хранение информационных средств труда и предметов труда, или источников их получения.

Процессы хозяйственной деятельности предприятия, представленные на рисунке внутри контура управления, реализуются его работниками - внутренними человеческими ресурсами предприятия.

Зона ответственности руководителей подразделений среднего звена управлений, самого много уровневого звена в иерархических корпоративных структурах, представлена тактическим управлением - распределением тактических задач своего уровня управления на оперативные задачи подчиненных подразделений. Эту декомпозиционную вертикальную цепочку на рисунке представляет первая - объектно-целевая составляющая процессов. Оперативные задачи исполнителям на короткие периоды (недели и дни) ставят руководители 


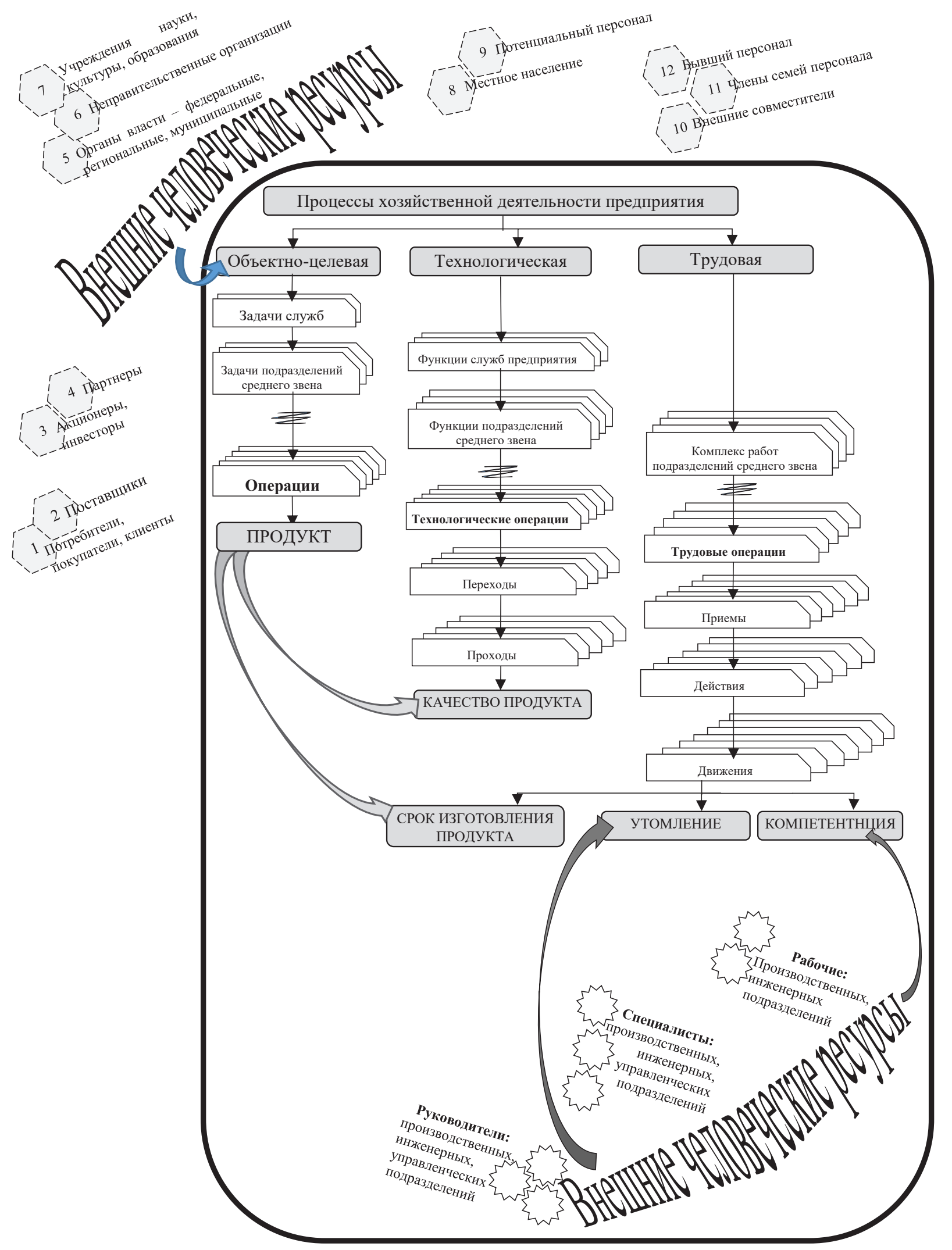

Рис 1. Редукция процессов хозяйственной деятельности предприятия 
первичных звеньев. Корректирует состав ежедневных задач, и распределяют их на операции сами исполнители соответствующих подразделений в соответствии с требованиям и технологических регламентов. Декомпозиция объектно-целевой составляющей - первична, так как она позволяет обеспечить продуктовую направленность процессов, ради которых и создавалось само предприятие.

Вторая составляющая процессов - технологическая, ее назначение обеспечить требуемое качество создаваемого продукта. В терминах коллективного трудового процесса - подобрать такие инструменты, оснастку и способы обработки предмета труда, чтобы на выходе процесса получить требуемое качество продукта.

Согласно обязательствам перед акционерами, руководство предприятия, прежде всего, должно обеспечить им получение прибыли за счет своей оперативной производственной деятельности, а при долгосрочных инвестициях, не только сегодня, но и в будущем. Согласно статье 212 ТК РФ работодатель обязан обеспечить соответствующие требованиям охраны труда условия труда на каждом рабочем месте, при этом на практике - организация труда, включая организацию рабочих мест работников, традиционно входит в зону ответственности непосредственных руководителей - руководителей низового звена.

Третья составляющая процессов хозяйственной деятельности - трудовая. Назначение проектирования трудового процесса, в отличие от двух предыдущих, определяется не только в отношении продукта, но и в отношении работников, которые на высокотехнологичных предприятиях рассматриваются как стратегический ресурс. В результате правильно выстроенного трудового процесса минимизируются непроизводительные затраты, сокращается общая продолжительность процесса, с меньшей скоростью растем утомления и снижается работоспособность исполнителей в течение рабочего периода, а квалификация - растет.

Разнообразие видов профессиональной деятельности и организационных условий их протекания, вариабельность самих процессов и форм и описания приводят к необходимости постоянного развития как информационных систем управления процессами, так и компетенций персонала по их анализу и систематизации.

\section{7. Выводы}

1. Корпоративные структуры высокотехнологичных отраслей экономики, являясь локомотивами инновационного развития России, обеспечивая ее и собственное долгосрочное развитие, включают в состав ключевых параметров корпоративного управления бизнес-процессы.

2. К бизнес-процессам относят разверстку во времени базовых бизнес-функций - управление производством, управление рынком, управление, финансами, управление человеческими ресурсами, управление НИОКР и разработкой продукции, в представленном или модифицированном перечне.

3. Все бизнес - процессы включают в себя как поисковые процессы, реализуемые в условиях высокой неопределенности, так и повторяющиеся процессы, подлежащие исследованию, систематизации, анализу, оптимизации, регламентации.

4. Осваивать эти компетенции возможно только на «ходу», находясь внутри процессов на принципах работы обучающейся организации.

5. Отраслевые научные организации, профильные и корпоративные университеты должны обеспечить это направление не только концептуальными разработками, но и комплексами учебно-методических тренажеров по формированию и развитию компетенций по анализу и оптимизации процессов работы на каждом уровне управления.

6. Поддержать подготовку профессиональных специалистов по анализу и оптимизации процессов для специализированных подразделений в составе предприятий и Управляющих компаний (Корпоративных центров).

7. В составе обязанностей в должностных регламентах руководителей всех уровней и специалистов, в разделе «Должностные обязанности» следует выделить два подраздела «Функциональные обязанности» и «Организационные обязанности».

8. В разделе «Организационные обязанности» должностной инструкции специалистов отразить обязанности по анализу и оптимизации собственного трудового процесса, так и по организационным коммуникациям со смежниками.

9. В разделе «Организационные обязанности» должностных регламентов руководителей обязанности по отношению к внешним и внутренним человеческим ресурсам внутреннего и внешнего контура управления. 


\section{Библиографический список}

1. Дементьева А.Г. Обучающаяся организация в современной системе развития персонала компании // Экономика и право. 2018. № 5 (119). С.115-119.

2. Новая редакция Трудового кодекса РФ с изменениями на 2018 год.

3. Бухалков М.И. Производственный менеджмент: организация производства: учебник, 2-е изд. Москва. 2015. 395 c.

4. Базадзе Н.Г. Организационное проектирование и развитие управленческого потенциала наукоемкого производства: монография. Москва. 2002. 228 с.

5. Деминг Э. Выход из кризиса. Новая парадигма управления людьми, системами и процессами/ Пер. с англ. Москва. 2007. 370 с.

6. Манн Д. Бережливое Управление бережливым производством /Пер. с англ. Москва. 2009. 208 с.

7. Наумов А.А. Управление бизнес-процессами: монография. Москва. 2011. 172 с 